DOI: 10.18468/letras.2017v7n1.p137-164

\title{
ORIENTAÇÃO SEXUAL NA IDENTIDADE DE GÊNERO A PARTIR DA CRÍTICA DA HETEROSSEXUALIDADE E CISGENERIDADE COMO NORMAS
}

\author{
Beatriz Pagliarini Bagagli ${ }^{1}$
}

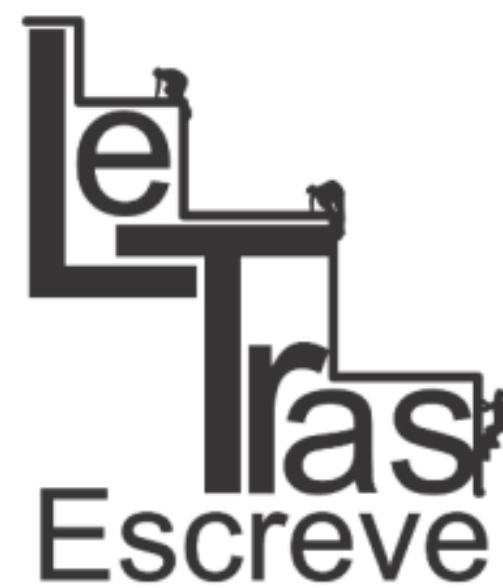

(ISSN 2238-8060)
RESUMO: Este artigo propõe discutir as formas de como as sexualidades das pessoas trans, transexuais e travestis, assim como dos seus eventuais parceiros cisgêneros, são socialmente interpretadas. Para tanto, iremos partir de um referencial teórico sobre os estudos de gênero e sexualidade e dialogar com relatos e análises de pessoas trans. Observamos como identidade de gênero e orientação sexual, mesmo pertencentes a esferas distintas de constituição de subjetividade, se interseccionam. Pretendemos compreender como estes processos de subjetivação se dão a partir não apenas de uma crítica à heterossexualidade compulsória, mas também à cisgeneridade compulsória. Há, portanto, um ponto em que a crítica à normatividade da orientação sexual toca a crítica à normatividade da identidade de gênero e vice-versa.

Palavras Chave: Identidade de gênero; Orientação sexual; Estudos de gênero.

ABSTRACT: This article proposes to discuss the ways that sexualities of trans people, transsexuals and travestis, as well of their possible cisgender partners, are socially interpreted. To do so, we will use a theoretical framework on gender and sexuality studies and dialogue with narratives and analyzes of trans people. We observe how gender identity and sexual orientation, even both belonging on different spheres of constitution of subjectivity, intersect. We intend to understand how these subjectivation processes are based not only on a critique of compulsory heterosexuality but also on compulsory cisness. There is, therefore, a point where the critique of the normativity of sexual orientation touches the critique of the normativity of gender identity and vice versa.

Keywords: Gender identity; Sexual orientation; Gender studies.

\section{Introdução}

Os Princípios de Yogyakarta ${ }^{2}$ definem orientação sexual e identidade de gênero, respectivamente, da seguinte maneira:

\footnotetext{
${ }^{1}$ Universidade Estadual de Campinas. Graduada em letras, atualmente cursa Mestrado em Linguística.paglibagli@gmail.com

2 Princípios sobre a aplicação da legislação internacional de direitos humanos em relação à orientação sexual e identidade de gênero.
} 
A capacidade de cada pessoa de experimentar uma profunda atração emocional, afetiva ou sexual por indivíduos de gênero diferente, do mesmo gênero ou de mais de um gênero, assim como de ter relações íntimas e sexuais com essas pessoas. (ICJ, 2007)

A profundamente sentida experiência interna e individual do gênero de cada pessoa, que pode ou não corresponder ao sexo atribuído no nascimento, incluindo o senso pessoal do corpo (que pode envolver, por livre escolha, modificação da aparência ou função corporal por meios médicos, cirúrgicos ou outros) e outras expressões de gênero, inclusive vestimenta, modo de falar e maneirismos. (ICJ, 2007)

Partindo destas definições, podemos sublinhar que existem

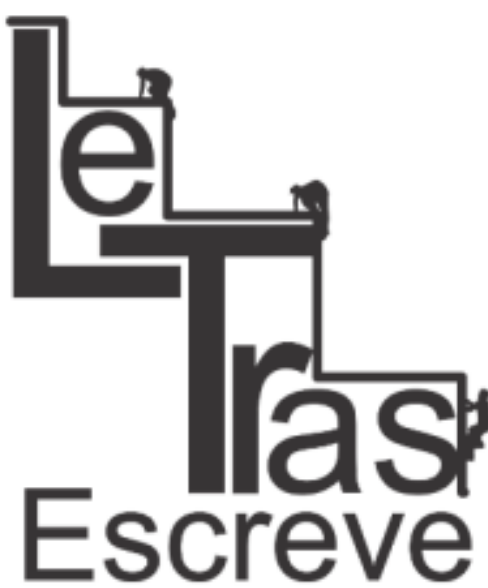

(ISSN 2238-8060)

sexualidades que envolvem a atração por indivíduos de gêneros iguais, diferentes ou por mais de um gênero - sendo designadas, respectivamente, como homossexualidade, heterossexualidade e bissexualidade - e identidades de gênero que podem corresponder ou não com as expectativas ${ }^{3}$ sociais sobre o sexo atribuído ao nascimento sendo designadas, respectivamente, como cisgênera ou transgênera ${ }^{4}$. Os estudos de gênero e sexualidade frequentemente levam em consideração tanto orientação sexual como identidade de gênero como recortes analíticos a fim de se visibilizar as questões políticas das mulheres e LGBT's. Contudo, há ainda uma lacuna que diz respeito à intersecção analítica e descritiva entre as identidades de gênero

\footnotetext{
${ }^{3}$ Acrescentamos este termo "expectativas" em relação à definição original dos princípios de Yokyakarta para ressaltar que as concordâncias ou discordâncias em relação às identidades de gênero são definidas a partir de expectativas sociais em relação a determinado gênero, e não apenas em relação ao "sexo atribuído ao nascer", no intuito de tornar nossas descrições mais precisas.

${ }^{4}$ De nossa perspectiva teórica e política, que se filia a partir dos diálogos entre os campos feministas e dos estudos de gênero, levamos em consideração a existência de múltiplas identidades transgêneras. Ressaltamos que enunciamos a partir de um contexto brasileiro, em que as travestilidades e transexualidades são mobilizadas como forma de reivindicação de direitos. Iremos usar a expressão "pessoas trans" neste artigo como forma de agrupar, sempre que for pertinente ao contexto em questão, travestis, homens e mulheres transexuais e demais pessoas que de alguma forma vivenciam seus gêneros para além da cisgeneridade.
}

https://periodicos.unifap.br/index.php/letras

Macapá, v. 7, n. I, Io semestre, 2017. 


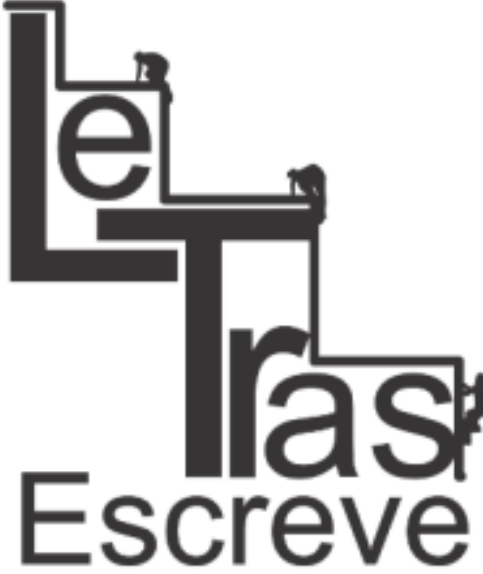

(ISSN 2238-8060)

contra-hegemônicas e as sexualidades contra-hegemônicas. Tal lacuna se dá através da segmentação excessiva como tais estudos têm sido feitos sobre essas questões - o que gera por vezes um efeito de invisibilização teórica e política da sexualidade dos sujeitos transgêneros (assim como dos sujeitos cisgêneros que se relacionam com pessoas transgêneras).

Desta forma, este artigo propõe refletir acerca das seguintes questões: como pensar a sexualidade daqueles sujeitos cujos corpos são incapazes de sustentar uma verdade quanto aos seus gêneros? Como é pensada a sexualidade dos sujeitos cujos corpos são ininteligíveis segundo as normas de cisgeneridade e como é pensada a sexualidade dos sujeitos que se atraem por eles?

Para tanto, iremos trazer uma bagagem teórica sobre os estudos de gênero e sexualidade, em especial aqueles que se propõem à análise das normas de gênero e sexualidade, e dialogar com e a partir dos relatos e análises de pessoas transgêneras acerca de suas vivências que envolvem a questão da sexualidade e afetividade.

Os estudos que buscam analisar as produções de efeito de clandestinidade e abjeção nas relações entre pessoas transexuais e cisgêneras costumam apontar a homofobia e a heterossexualidade compulsória (heteronormatividade) como causas deste efeito. Contudo, consideramos fundamental pensarmos tanto a categoria de transfobia como de cisgeneridade compulsória (cisnormatividade) como forma de análise destas relações de poder com o intuito de não incorrer no equívoco, no desenvolver da própria análise, de imiscuir a identidade de gênero na orientação sexual (como se fossem meramente e indiscriminadamente sinônimos).

Desta forma, não pretendemos desconsiderar as relações de poder que atravessam intersecionalmente tanto a identidade de 


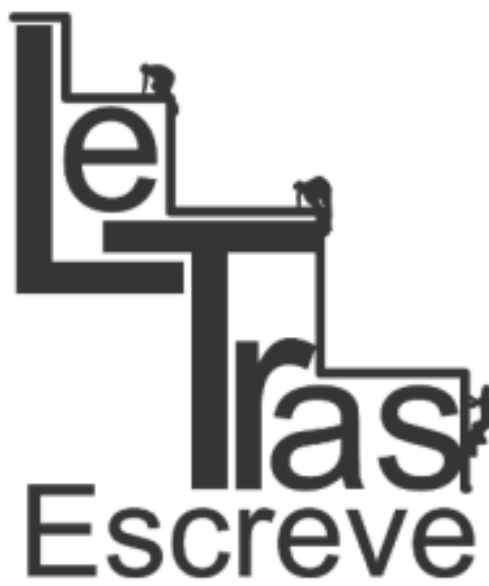

(ISSN 2238-8060)

gênero quanto à sexualidade não-hegemônicas (em relação à cisgeneridade e à heterossexualidade); entendemos, sim, que é preciso compreender como tanto as normas de gênero quanto de sexualidade se imiscuem na forma de produção de normas e exclusões de maneira a não apagar as especificidades que corcernem tanto as identidades de gênero contra-hegemônicas quanto às sexualidades contra-hegemônicas.

Assim, podemos compreender em que medida gênero e sexualidade se intersecionam na produção de efeitos e significados sociais na mesma proporção em que reconhecemos suas especificidades enquanto campos distintos - sem sobrepor equivocadamente um sobre o outro, evitando o apagamento das questões que corcernem propriamente às identidades de gênero inconformes à cisgeneridade hegemônica. Afinal, para compreensão do entrelaçamento entre orientação sexual e identidade de gênero, partimos da afirmação de Sedgwick (2007) de que o "problema da definição de gênero também influi sobre o problema da definição homo/heterossexual".

\section{Homossexualidades e normas heterossexuais}

Warner (1991) menciona que diversos ramos de teorias sociais têm dado importância para a conexão entre política e sexualidade. Nesta perspectiva, argumenta o autor, a luta para a construção de uma ordem não opressiva quanto ao gênero só pode se concretizar através de uma mudança radical na ordem da sexualidade, mesmo assumindo que a sexualidade seja parcialmente pertencente a um campo separado de pesquisa e ativismo (ibid. p.4).

Hocquenghem (2009) questiona a obviedade daquilo que poderia constituir um desejo heterossexual ou homossexual. 


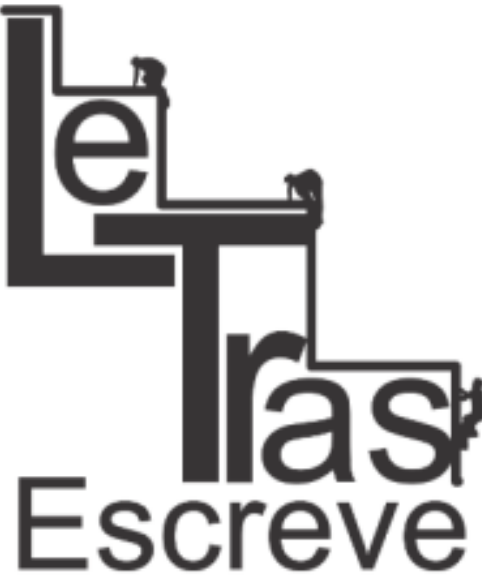

(ISSN 2238-8060)

Segundo o autor, tais designações não são auto evidentes, tanto o desejo heterossexual quanto homossexual consistem em "um recorte arbitrário e abstrato de um fluxo ininterrompido e polívoco" (p.22). A homossexualidade é caracterizada por ele como um fantasma que atormenta ao mesmo tempo em que excita o "mundo normal".

Berlant e Warner (1998) definem a heteronormatividade como um conjunto de "instituições, estruturas de compreensão e orientações práticas que fazem a heterossexualidade ser vista não apenas como coerente - ou seja, organizada como uma sexualidade mas também privilegiada" (p.548) e como um "motor fundamental para a organização da sociedade dos Estados Unidos" que produz relações de exploração e desigualdade dentro mesmo da própria sociedade heterossexual (p.564). Ela não é apenas sustentada pela circulação massiva dos discursos sobre o amor romântico, mas também através do casamento, leis de família, arquitetura doméstica, divisão do trabalho e política (ibid., p.562).

A designação "cultura heterossexual", também formulada por Berlant e Warner (ibid.), não se refere, segundo eles, a uma cultura completamente unificada, nem capaz de compartilhar as mesmas crenças e simbolismos, na medida em que a sua hegemonia não depende de uma mera monocultura. As hegemonias são nada além de alianças elásticas, envolvendo estratégias dispersas e contraditórias para a sua manutenção e reprodução (BERLANT, WARNER, ibid., p.553). Os autores afirmam que a cultura queer ${ }^{5}$, em contrapartida, carece da matriz institucional (heterossexual) para o estabelecimento de formas de intimidade e afetividade.

Jackson (2006) defende que o conceito de heteronormatividade deve levar em consideração, como forma de mobilização

\footnotetext{
${ }^{5}$ Queer é um termo de língua inglesa usado para designar, de forma abrangente, as pessoas que não se enquadram, de alguma forma, nas normas de gênero e sexualidade.
} 


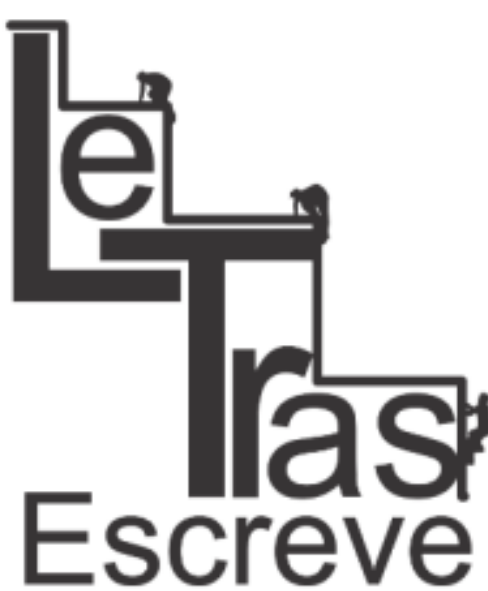

(ISSN 2238-8060)

analítica, uma dupla regulamentação social: daqueles que estão tanto dentro quanto fora da norma heterossexual. A autora também afirma que a regulação da heteronormatividade incide tanto sobre o gênero como sobre a sexualidade - mesmo assumindo que gênero e sexualidade sejam pertencentes a fenômenos de ordens diferentes. A heteronormatividade não incide apenas na regulação de práticas sexuais mas também tudo o que envolva um "estilo de vida normal" (JACKSON, ibid. p.107).

Rich (2010) qualifica a heterossexualidade enquanto compulsória e como um regime político capaz de apagar a existência das lésbicas, retirar as mulheres dos espaços de poder e legitimar a violência de gênero. A autora também rejeita uma hipótese psicanalítica sobre a dominação masculina em que se postula que o controle da sexualidade feminina seria decorrente do medo masculino de uma suposta "insaciabilidade sexual das mulheres"; ela então formula outra causa, incidindo agora na possível indiferença sexual das mulheres em relação aos homens, num modo de acesso sexual, afetivo e econômico que sê dê através dos termos exclusivamente femininos - deixando os homens na "periferia da matriz" (RICH, ibid., p.29).

Weeks (2000) afirma que a emergência dos termos "heterossexual" e "homossexual" marca um estágio crucial na delimitação e definição modernas da sexualidade ${ }^{6}$. 0 autor aponta que a significação de ambas as palavras se dá a partir da mútua relação que elas estabelecem entre si; contudo, tal relação não é de simetria, já que a heterossexualidade se define como norma em relação à anormalidade da homossexualidade. As discussões sobre esses termos envolvem

\footnotetext{
${ }^{6}$ Segundo o autor, "a pesquisa histórica recente tem demonstrado que não apenas outras culturas não têm essa forma de ver a sexualidade humana [a partir da divisão entre homossexualidade e heterossexualidade], como também não a tinham as culturas ocidentais, até mais ou menos recentemente" (ibid. p.45).
} 
processos em que a redefinição da norma e a definição do que constitui anormalidade estão inextricavelmente ligados (WEEKS, ibid.). Segundo o autor, na medida em que se compreende a história da homossexualidade, pode-se ter uma nova compreensão da heterossexualidade e da sexualidade como um todo.

A intrincada relação entre homossexualidade (enquanto "outro" da norma, e identidade "alternativa") e heterossexualidade (enquanto norma e sexualidade hegemônica) é descrita por Louro (2000), da seguinte maneira:

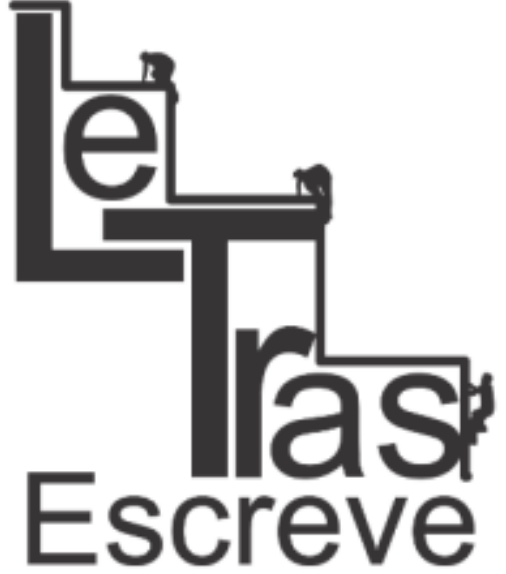

(ISSN 2238-8060)

as instituições e os indivíduos precisam desse "outro". Precisam da identidade "subjugada" para se afirmar e para se definir, pois sua afirmação se dá na medida em que a contrariam e a rejeitam. Assim, podemos compreender por que as identidades sexuais "alternativas", mesmo quando excluídas ou negadas, permanecem ativas (e necessárias): elas se constituem numa referência para a identidade heterossexual; diante delas e em contraposição a elas a identidade hegemônica se declara e se sustenta. (p.21)

Segundo Louro (2000, ibid., p.6) a sexualidade não surge espontaneamente como uma experiência natural, pois envolve "rituais, linguagens, fantasias, representações, símbolos, convenções, processos profundamente culturais e plurais". Nesta perspectiva, as formas de expressão de sexualidade são socialmente estabelecidas e codificadas, assim como a inscrição do gênero - masculino ou feminino nos corpos. Pelo fato de serem sociais, as identidades de gênero e sexuais são moldadas pelas redes de poder (LOURO, ibid.). A autora também afirma que pelo fato da sexualidade e gênero adquirirem uma centralidade ${ }^{7}$ para a existência dos sujeitos ocidentais, os pro-

\footnotetext{
${ }^{7}$ Centralidade quanto à da identidade sexual para a constituição de uma unidade essencial do sujeito.
} 


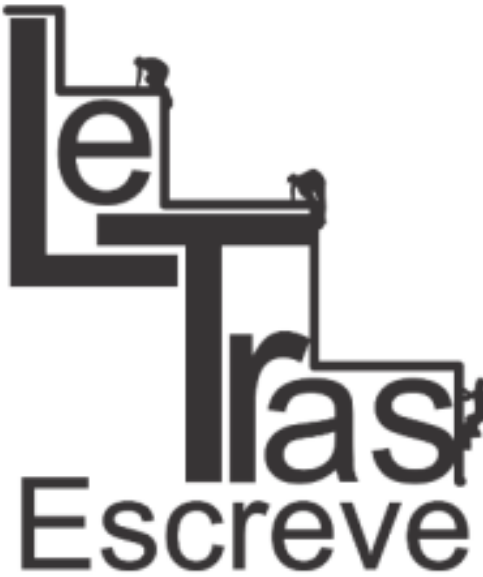

(ISSN 2238-8060)

cessos de constituição de subjetividade que envolvam características como as de indeterminação, fluidez ou dissolução, foram relegados ao campo do indesejável, abjeto, perturbador ou perigoso.

Weeks (2000, p.25) argumenta que "embora o corpo biológico seja o local da sexualidade, estabelecendo os limites daquilo que é sexualmente possível, a sexualidade é mais do que simplesmente o corpo [...] tem tanto a ver com nossas crenças, ideologias e imaginações quanto com nosso corpo físico". O autor também define a sexualidade como uma "construção social e uma invenção histórica com base nas possibilidades do corpo", levando em consideração que "as culturas fornecem categorias, esquemas e rótulos muito diferentes para enquadrar experiências sexuais e afetivas".

A categoria do corpo na sua relação com a sexualidade passa a se tornar uma questão central para a compreensão da sexualidade das pessoas trans ou das pessoas que se relacionam com elas. É por meio do corpo que o sexo é significado e também é por meio dele que a sexualidade das pessoas trans e daquelas que se relacionam com elas é posta em uma posição de excepcionalidade - não se sabe qual é a sexualidade das pessoas trans e das pessoas que se relacionam com elas na medida em que não se sabe como interpretar, posicionar, classificar, ler ou simbolizar os corpos trans. Corpos não "suficientemente" femininos, nem "suficientemente" masculinos, a partir de uma referência cisgênera para tal suficiência, desvelarão a disputa pela definição do que viria a ser uma "sexualidade verdadeira".

\section{Pessoas de verdade ou cisgeneridade normativa?}

Lomando (2014) aponta que as diferentes metáforas usadas para descrever as experiências de trânsito de sexo/gênero como ora do campo da psicopatologia ora como do campo da construção social 


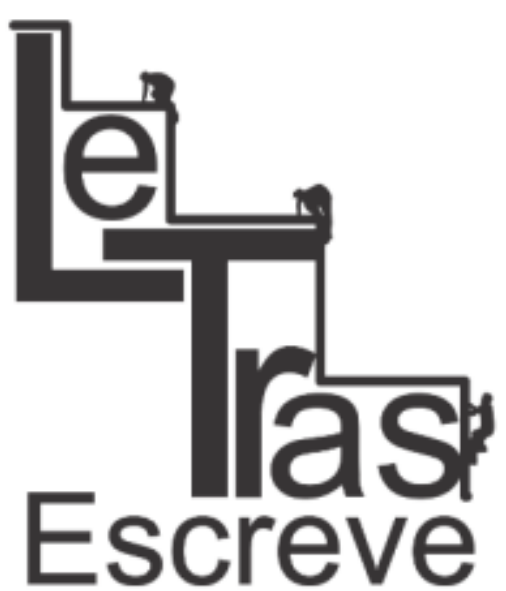

(ISSN 2238-8060)

da identidade desvelam o caráter de "campo de batalha" das disputas que concernem às questões de gênero no âmbito intelectual e científico. Tais metáforas também incidem sobre aquelas experiências de não-trânsito de gênero, como nas construções "homens e mulheres biológicos, verdadeiros, de nascença" ou também cisgêneros para designar o antônimo de homens e mulheres transexuais.

O uso de uma ou outra construção linguística ou palavra desvela, neste caso, distintas concepções teóricas e políticas sobre gênero e sobre o estatuto da verdade e legitimidade das identidades transgêneras - tendo em vista o teor não simétrico dos efeitos de sentidos entre a designação "biológica" e "cisgênera" para qualificar as identidades de gênero. Neste aspecto, Lomando (ibid., p.47-48) se indaga,

Primeiro de tudo, quando nós lemos os termos muIher de nascença, homem ou mulher biológico, e, especialmente, homem de verdade, a primeira coisa que nós nos questionamos é qual são os seus opostos? Se o HC [homem cisgênero] é "biológico" ou "verdadeiro", isso faz do HT [homem transgênero] artificial, não verdadeiro, mentiroso, falso, ficcional ou virtual? Nós compreendemos que a resposta para essa pergunta pode ser outra pergunta: O que significa ser homem ou mulher? Quais são as variáveis que nós usamos para defini-los? Alguns poderiam responder ter um pênis ou vagina "de verdade". Mas estes critérios podem ser usados sozinhos para definir um homem ou uma mulher? As experiências trans demonstraram que ser ho$\mathrm{mem} /$ mulher é muito mais do que isso e não é definido por possuir determinada genitália. Desta forma, o termo "homem de verdade" e outros produzem uma metáfora excludente. ${ }^{8}$

A cisgeneridade é entendida por Vergueiro (2016) como um eixo que constitui uma matriz de práticas repetidas que todas as pes-

\footnotetext{
${ }^{8}$ Tradução nossa.

https://periodicos.unifap.br/index.php/letras

Macapá, v. 7, n. I, Io semestre, 2017.
} 


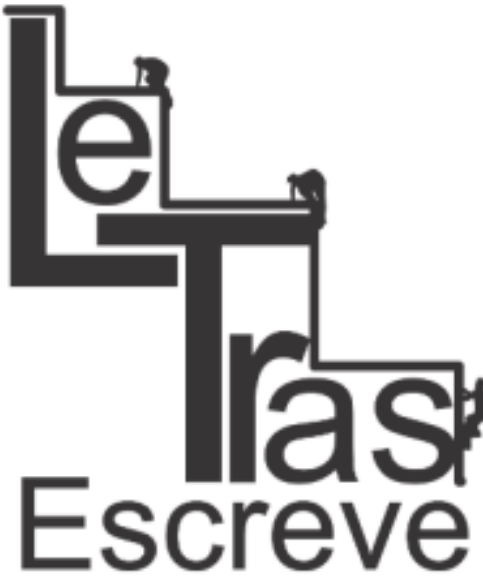

(ISSN 2238-8060)

soas são impelidas para performar ${ }^{9}$ na produção de coerências e evidências acerca do sexo e também como "um conjunto de dispositivos de poder colonialistas sobre as diversidades corporais e de gênero, sendo tais dispositivos atravessados por outras formas de inferiorização, marginalização e colonização interseccionais" (p.72).

O funcionamento desta matriz, argumenta Vergueiro (ibid.), exige com que certos tipos de identidade não possam existir ou então serem tidos como inviáveis. Desta forma, há uma relação intrínseca entre a produção de coerências por esta matriz cisnormativa e a exclusão (constitutiva) das transgeneridades, relação esta que produz efeitos de abjeção e subalternidade sobre as identidades ininteligíveis. As contribuições teóricas de Vergueiro, que dialoga com Butler (2003), nos permitem compreender como a cisnormatividade e heteronormatividade se sustentam mutuamente em seus efeitos nas produções das identidades inteligíveis nos campos, respectivamente, da identidade de gênero e orientação sexual.

A origem do uso da cisgeneridade como conceito analítico, segundo Vergueiro (ibid.), se deu em interações sociais e iniciativas de ativismos trans como forma de resistência às instâncias teóricas unitárias e coloniais. Segundo a autora, a cisgeneridade como norma se fundamenta através de três eixos naturalizados e interdependentes entre si acerca das identidades e corpos: pré-discursividade, binariedade e permanência.

\section{Relações afetivas e sexuais entre metáforas e armários}

Lomando (2014) aponta que a criatividade na forma como os

\footnotetext{
${ }^{9}$ Vergueiro (2016) dialoga a partir de contribuições teóricas de Butler (2003) para mobilizar as noções de performatividade e o seu funcionamento como matriz de gênero e identidades inteligíveis.
}

https://periodicos.unifap.br/index.php/letras

Macapá, v. 7, n. I, Iㅇ semestre, 2017. 


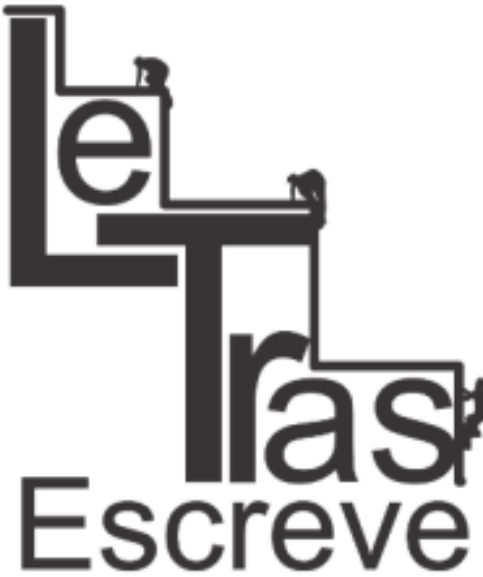

(ISSN 2238-8060)

casais formados por cônjuges transgêneros ${ }^{10}$ narram e nomeiam suas identidades e relacionamentos (criando metáforas singulares para além do binarismo de gênero) é capaz de desestabilizar uma taxonomia de gênero normativa.

O autor também analisa, a partir de entrevistas, as negociações que alguns casais faziam no campo da sexualidade, já que para algumas pessoas transexuais, certas áreas ou partes de seus corpos, vistas por elas mesmas ou na relação com seus parceiros/as, implicam algum grau de desconforto. Os aspectos corporais que podem gerar disforia para as pessoas transexuais são aqueles ligados, principalmente, aos genitais e a área peitoral (presença ou ausência de glândulas mamárias desenvolvidas), e que estão fortemente associados às leituras sociais de gênero que delimitam o que é considerado feminino ou masculino.

De nossa posição, entendemos que a disforia corporal que muitas pessoas trans podem experienciar não marca nenhum destino ou essência do que seja uma identidade em inconformidade com a cisgeneridade. Também não assumimos que a existência da disforia se dê sob o resultado de alguma forma de auto alienação por parte destes sujeitos, como se pessoas trans só experienciassem disforia em decorrência de uma suposta reprodução consentida de normas sociais. A partir das análises de Lomando podemos concluir que as disforias não são as mesmas entre todas as pessoas trans, e que as pessoas trans encontram muitas vezes maneiras de subjetivarem seus corpos de forma a resistir aos imperativos normativos a partir da singularidade e criatividade de suas vivências.

Soares (2012) aponta que as relações afetivas que envolvem pessoas transexuais foram historicamente patologizadas pelos sabe-

\footnotetext{
${ }^{10}$ Todos os casais estudados pelo autor envolviam um cônjuge transgênero e outro cisgênero.
}

https://periodicos.unifap.br/index.php/letras

Macapá, v. 7, n. I, Io semestre, 2017. 


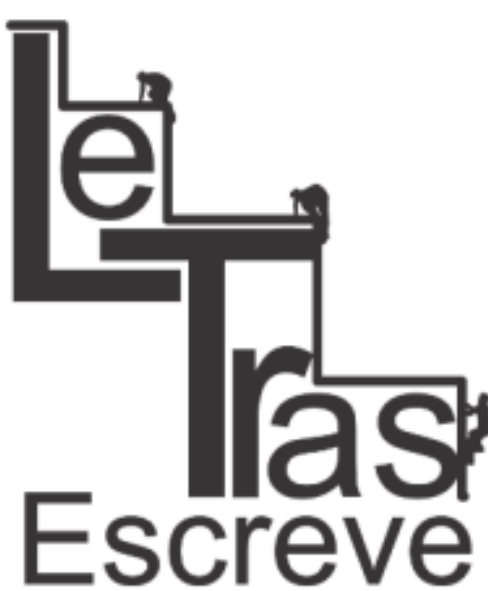

(ISSN 2238-8060)

res da psiquiatria, o que se exemplifica na criação de termos com teor diagnóstico como "folie à deux"11 e "ginandromorfofilia". O primeiro termo associa o fato do parceiro/a da pessoa transexual assumir a identidade de gênero do seu parceiro/a como legítima a uma espécie de "delírio compartilhado"; já o segundo assume que toda forma de desejo por mulheres transexuais se constituiria como uma espécie de parafilia. A autora afirma que homens que buscam relacionamentos afetivo-sexuais com mulheres transexuais sentem "angústias, medos, estigmas por não se engendrarem no binômio heteroerótico-homoerótico". Neste sentido, sensações de ansiedade e angustia podem emergir pela dificuldade dos parceiros das mulheres transexuais em compreenderem suas orientações sexuais para além de modelos hegemônicos de feminilidade e masculinidade binários (SOARES, ibid.).

Pelúcio (2006) menciona que travestis têm a percepção de que estão em constante risco de serem abandonadas por seus parceiros. A situação de clandestinidade e estigma são os principais motivos para que as próprias travestis se vejam em uma posição de preterimento afetivo (em uma relação de competição com as mulheres cisgêneras ${ }^{12}$ ), fazendo com que muitas vezes se sintam coagidas a terem que relevar situações a princípio inaceitáveis, como a da traição do cônjuge, para manterem o relacionamento. A autora também afirma que o estigma que pesa sobre as travestis "contamina" os seus parceiros homens (cisgêneros) e também que as relações entre travestis e homens não estão isentas de reproduzirem

\footnotetext{
${ }^{11}$ A expressão pode ser traduzida como "loucura a dois", o que indica que as relações sexuais e afetivas que envolvam pessoas transexuais eram associadas pelo discurso médico a uma espécie de delírio que seria compartilhada pelo casal.

12 Pelúcio (2006, p.529) afirma que as mulheres cisgêneras, a partir de um relato expresso por uma travesti em relacionamento com um homem cisgênero, "tem de certa forma prerrogativas que tornam legítima ou, no mínimo, menos dolorosa a traição e mesmo a troca de parceira".
}

https://periodicos.unifap.br/index.php/letras

Macapá, v. 7, n. I, Io semestre, 2017. 


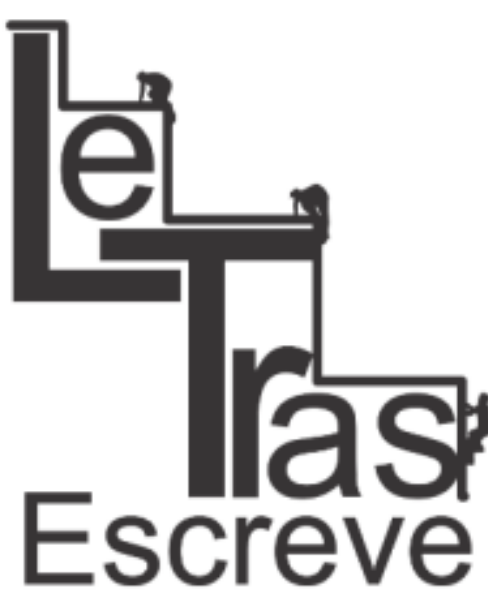

(ISSN 2238-8060)

os aspectos normativos do modelo heterossexual (como os papéis esperados de uma esposa e marido heterossexuais).

Tannehill (2014) afirma que os corpos e as histórias das pessoas transgêneras são vistas como se fossem de domínio público, o que infringe diretamente o direito à intimidade e privacidade. Tais violações se mostram ainda mais evidentes quando envolvem questões de sexualidade e parcerias afetivas. A autora afirma isto para denunciar as formas de justificação de violências (ou atenuação de culpabilidade dos agressores) contras pessoas transgêneras com base no fato delas simplesmente não contarem (ou omitirem) que são transgêneras - principalmente em contextos em que as pessoas trans são alvo de parceria afetiva e/ou sexual.

Tais justificativas estão presentes inclusive na atenuação de penas em tribunais para agressores de pessoas trans assim como na punição de pessoas trans acusadas de estupro tão somente pelo fato de não assumirem sua transgeneridade para os seus parceiros ${ }^{13}$. A ideia subjacente a tais raciocínios é de que a condição de transgeneridade, por ser considerada de alguma forma indesejada por supostamente representar uma espécie de engodo, precisa ser revelada a qualquer custo (especialmente para parceiros sexuais em potencial), e caso não seja, de alguma forma se legitima ou justifica as eventuais formas de violência que a pessoa transgênera passa a estar exposta pela sua "ousadia" em omitir sua identidade.

Sedgwick (2007) mostra que a metáfora do armário para representar as delimitações entre público/privado; revelação/segredo ou dentro/fora incide não apenas propriamente no âmbito da sexua-

\footnotetext{
${ }^{13}$ Tannehill (2014) cita um caso, na Austrália, em que um policial revelou (ilegalmente) a um homem que sua parceira era uma transexual operada e, ao chegar em casa, esse homem a agrediu violentamente; a pena contra o policial que divulgou ilegalmente tal informação foi leve; a autora também cita que na Escócia um homem transgênero foi acusado de estupro e colocado na lista de criminosos sexuais por não revelar sua condição à namorada antes de uma relação sexual consensual.
}

https://periodicos.unifap.br/index.php/letras

Macapá, v. 7, n. I, Io semestre, 2017. 
lidade, mas também na própria cultura ocidental. $\mathrm{O}$ armário é a característica fundamental da vida social para pessoas gays e é a estrutura definidora da opressão gay no século XX, segundo a autora.

Neste aspecto, partindo destas considerações sobre o armário, podemos pensar acerca de especificidades próprias às questões de identidade de gênero, no que se refere ao mecanismo social de revelação e ocultamento da condição transgênera. Podemos pensar o armário enquanto um dispositivo que controla os processos de desvelamento compulsório da identidade transgênera tendo em vista o funcionamento de um discurso sobre a verdade dos sexos.

\section{Vivências e análises trans}

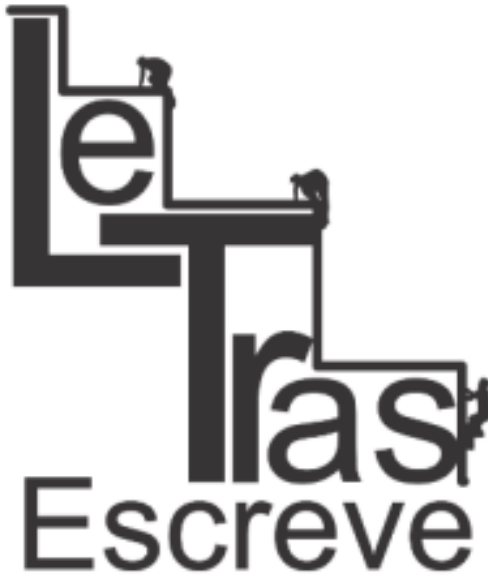

(ISSN 2238-8060)

Araújo (2015a) afirma que o campo da afetividade (e por contiguidade, podemos mencionar também da sexualidade) das travestis e mulheres trans negras se encontra ainda negligenciado nas discussões feministas. A autora busca resgatar as discussões do feminismo negro acerca da solidão da mulher negra para pensar questões transfeministas de forma a intersecionar questões de raça e de identidade de gênero.

É muito comum quando conheço outras mulheres trans e travestis, nos sentarmos e conversamos sobre situações que todas já vivemos. Dentro desse monte de vivências, as questões amorosas sempre parecem ser onde mais estamos em concordância umas com as outras. "Sim, também foi assim comigo.", "Antes era "oi, princesa", daí eu disse que era trans e já mudou e chamou pro motel.", "Nunca namorei.", "Queria ir com algum ao shopping de mãos dadas" e por aí vai. Embora possamos ser de raças ou classes sociais diferentes, nossas experiências, ainda assim, soam muito similares. [...] Mulheres que fogem do que é lido a partir de normas so- 
ciais como "ideal", frequentemente, são sujeitadas a vivenciar no campo amoroso não só uma exclusão, mas frequente uma desvalorização e desrespeito, quando somos divididas em castas das que "são pra comer" e as que "são pra casar". Sendo as para comer negras, gordas, trans e outras que fujam do padrão e as para casar, as que mais se aproximem de um modelo normativo. (ARAÚJO, ibid.)

A autora argumenta que é pela existência da transfobia que muitos homens deixam de assumir relacionamentos tidos como "sérios" com travestis e transexuais de forma a restringir às formas de relacionamento ao "sexo casual ou relacionamentos às escondidas". É a transfobia social e a produção de efeitos de estigmas, segundo Araújo (ibid.), que transforma um possível relacionamento entre ho-

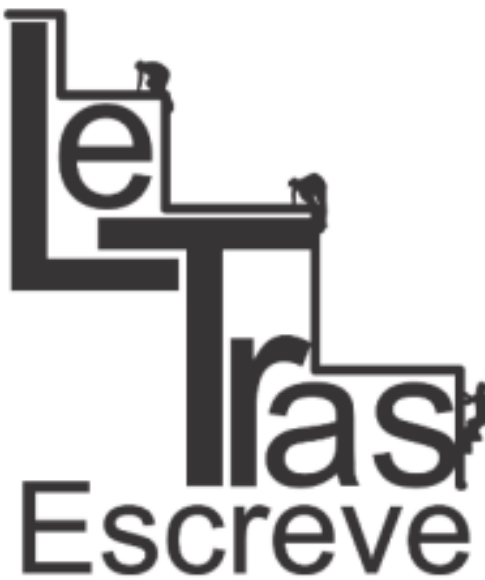

(ISSN 2238-8060) mens cisgêneros e mulheres transgêneras em uma "situação vexatória" que deve, a todo custo, ser ou evitado ou mantido em segredo. A autora conclui que o fato da população trans não ser vista como passível de receber afeto se imbrica com a produção de desumanização desta população e de precarização de vidas tidas como abjetas. A solidão da mulher trans e travesti, portanto, não decorre de um pretenso preterimento afetivo no nível de escolhas individuais, mas, sim, de uma estrutura que institui normas, o que impacta na forma como os indivíduos se relacionam afetivamente.

Na medida em que o relacionamento afetivo com uma travesti ou mulher trans implica o questionamento (enquanto uma ameaça iminente) da heterossexualidade masculina, as interpretações sociais condicionam estes relacionamentos a serem vistos ora como vergonhosos, ora como motivos de interdições e denegações. Araújo (2015b), partindo de um exemplo de sua própria vivência, conta que a família de um namorado seu o expulsou de sua própria casa em virtude do seu relacionamento assumido com ela, que é travesti. Este 
caso mostra que a condição de estigma social que envolve as identidades trans é tamanha a ponto de atingir também pessoas cisgêneras que eventualmente se relacionem com pessoas trans.

Araújo (ibid.) também cita o caso de um jogador de futebol famoso ${ }^{14}$ como um sintoma destes estigmas: o jogador teve que vir a público "explicar" o fato de ter se envolvido com travestis profissionais do sexo e manifestar o seu "arrependimento" e "vergonha", pois havia sido "enganado", o que é noticiado como um "escândalo" pela mídia.

Segundo Soares (2012, p.118),

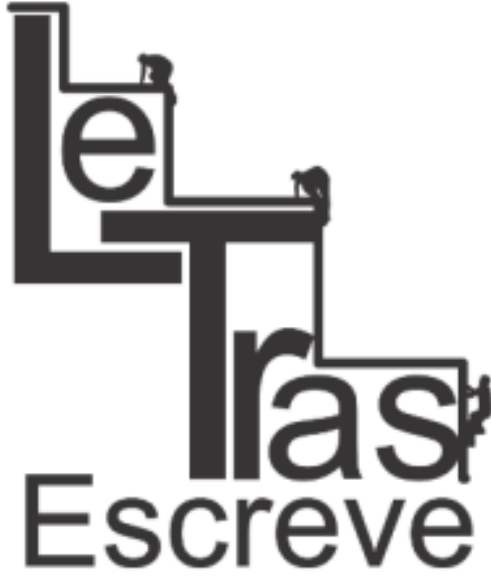

(ISSN 2238-8060)
É muito comum as pessoas entenderem a vivência de um homem parceiro de uma transexual como se esse homem fosse um homossexual "enrustido", sem coragem para assumir perante a sociedade sua orientação sexual. Isso o expõe a um estigma ainda mais degradante e que o distancia ainda mais dos padrões de masculinidade exigidos, uma vez que soma homossexualidade e covardia.

A questão da "coragem" aparece aparentemente como um paradoxo, na medida em que homens são vistos como covardes por supostamente não assumirem a sua "verdadeira" orientação sexual ao mesmo tempo em que são profundamente estigmatizados se ousam assumi-la, como relata Roxy (2017), abaixo. A ideia de que parceiros de pessoas transexuais e travestis estariam se "enganando" ou tentando enganar os outros e a própria sociedade no que se refere a sua orientação sexual é reflexo de como as identidades das pessoas trans são socialmente percebidas (igualmente como uma espécie de mascaramento da verdade, resultado de um engodo em relação ao próprio gênero). É neste ponto de cruzamento entre sexualidade e

\footnotetext{
${ }^{14}$ Em 2008, Ronaldo Nazário dá entrevista ao programa Fantástico com o intuito de "explicar" seu envolvimento com travestis.
} 
gênero que podemos observar relações de poder na discursivização da orientação sexual dos/as parceiros/as de travestis e transexuais.

Em uma sociedade onde somos ridicularizadas e ao mesmo tempo hipersexualizadas, assumir relacionamento com uma de nós, sei que não é fácil. Lembro quando um ex namorado assumiu publicamente seu relacionamento comigo. Nossos amigos questionavam a orientação sexual dele e especulavam seu papel na cama comigo. E pra um homem hétero cisgênero, ser questionado sobre essas coisas é ferir seu orgulho e masculinidade. E verdade seja dita, ninguém gosta de passar por isso, inclusive nós que somos transexuais. Infelizmente a sociedade pressupõe que homens que se relacionam com alguma de nós ou é bissexual ou é homossexual. Mas nunca passa na cabeça das pessoas que eles podem SIM ser heterossexuais. [...] Existem exceções de homens que assumem um relacionamento conosco! Que se sentem encorajados a enfrentar qualquer coisa pra estar junto. Conheço amigas que são casadas e são felizes. Mas como falei, são exceções. (ROXY, 2017)

Santos (2017) relata a sua própria vivência enquanto homem cisgênero casado com uma mulher transexual. Ele também descreve as dificuldades de assumir o relacionamento em função das normas sociais e dos estigmas transfóbicos. A questão da vergonha aparece novamente como uma imposição social a ser superada, e o fato dele conseguir suportar este "amor pesado", segundo ele, diz respeito a sua "hombridade" e a necessidade de se manter inteiro. O que antes poderia ser visto como uma fraqueza e covardia, como mencionou Soares, para Santos, é sinal de coragem e resistência.

É muito difícil um homem cis assumir publicamente uma relação amorosa com uma transexual ou travesti (...) Hoje casado com uma transexual percebo os olhares, as falas, as discussões, os encantos e desencantos, o desrespeito, as cartas que são deixa-

https://periodicos.unifap.br/index.php/letras

Macapá, v. 7, n. I, Io semestre, 2017. 


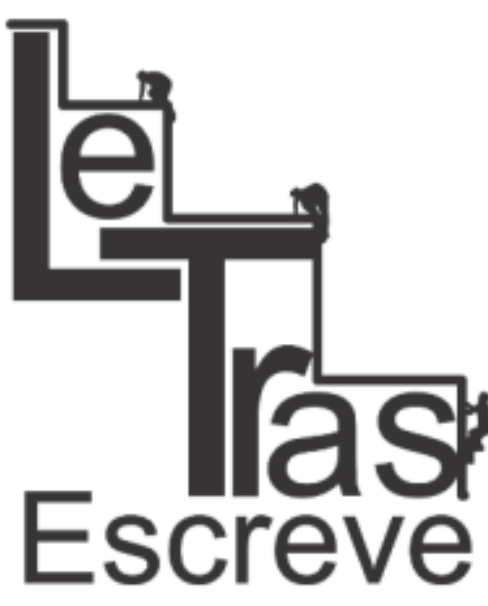

(ISSN 2238-8060) das na mesa quando almoçamos em algum lugar, os olhares atravessados e cortantes quando estamos no transporte público, as cabeças desejantes, nas ruas, bares, nas buzinas dos carros, nos lugares e espaços. Noto com muito pesar que a transfobia recai sobre mim, e sentindo o peso disso tudo penso algo peculiar: a vergonha a ser suportada faz com que quase todos os homens cisgênero não assumam relacionamentos com trans. Amar se torna muito mais pesado, é uma escolha que vai depender muito de nossa hombridade. (...) A minha experiência é que amar uma transexual é algo que me mantém inteiro. Escolhi lutar na contramão. Minha concepção de masculinidade não se diminui e sim me fortalece, não por conta do meu esclarecimento, mas por conta da luta travada aos padrões e paradigmas sociais. Isso faz com que eu me sinta pronto para amar independente da forma. Gostaria de ser exemplo para outros homens cis. (...) O destino dos homens cis que sentem desejos reprimidos por travestis e transexuais será sempre o submundo, a não ser que encarem a luta LGBT como sua também. (SANTOS, 2017)

González Gil (2017) descreve e analisa diversos aspectos que envolvem os relacionamentos com pessoas trans - como a questão do armário, a vergonha e a coragem. A autora afirma que falar de amor, para pessoas trans, é algo desde sempre delicado, pois é algo que envolve dor e é como se tivéssemos que caminhar sobre cascas de ovos - as pessoas trans se encontram frequentemente numa posição de não poderem "incomodar" seus parceiros com seus problemas. A posição daquelas pessoas (presumidamente cisgêneras) que se relacionam com pessoas trans também é analisada precisamente através de um não-lugar: poucas pessoas se mostram abertas a falarem que sentem ou podem sentir atração por pessoas trans - "ninguém sabe quem são os nossos parceiros e nossos parceiros não conhecem ninguém como eles", afirma a autora. A invisibilidade das pessoas trans, de certa forma, atinge também os seus potenciais par- 
ceiros - não se compreende o que eles sentem e o que sejam no que

diz respeito às suas sexualidades.

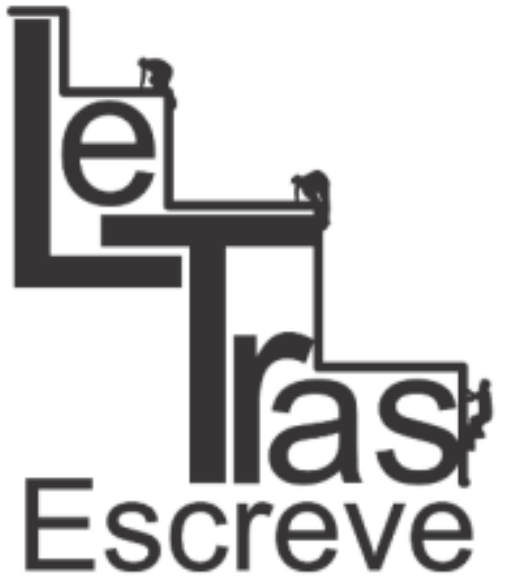

(ISSN 2238-8060)
Las relaciones más cercanas de las personas trans están determinadas por un mensaje en donde el amor convive con la violencia, el abuso, la vergüenza y la discriminación. Hemos naturalizado que para nosotras el amor, inevitablemente, implica hacernos un poquito de daño. El hecho de que pocas personas acepten públicamente que les atraen las personas trans ha implicado que hablar de amor sea como caminar sobre cáscaras de huevo. No queremos que nuestras parejas se enfaden con nosotras por hablar de ellas. Nos da miedo no volver a ser amadas y no discutimos temas que puedan generar confrontaciones, tampoco hablamos con nadie de ellos porque no queremos sacarlos del closet. Nadie sabe quiénes son nuestras parejas. $Y$ nuestras parejas no conocen a otras personas como ellos: nos dicen constantemente que quieren conocer a más personas como ellas (pero pocas se atreven a dar el primer paso y salir del closet). Pareciera que cuesta mucho decir que les gustan la vergas de sus novias, que sus novias son trans y que a ellos les gustan las trans. Muchas mujeres trans hemos estado en relaciones con manes que nos dicen que nos aman pero que es díficil para ellos presentarnos en su casa y al mundo como sus novias. A muchas las maltratan, les pegan, las infantilizan, les pegan y las degradan, pero igual les dicen "te amo". Como a las mujeres trans no nos reconocen como mujeres, vivir la violencia de género nos pone en una encrucijada muy retorcida: no sabemos si el maltrato que nos ocurre por ser mujeres es malo o si al contrario, es uno de esos pocos espacios donde nos reconocen como mujeres. Nuestra experiencia es que la violencia nos legitima como mujeres y eso es absolutamente preocupante. [...] Para las personas trans se hará el amor cuando las personas que queremos puedan expresar de forma abierta y honesta acciones de cuidado afecto, responsabilidad, respeto, compromiso y confianza hacia nosotras. El amor se hace donde existe la posibilidad de ser vulnerable y de compartir intimidad, no donde tenemos que estar a la defensiva. Las acciones que constituyen el amor solo son posibles en mundos donde no hay 
vergüenza en tener hijos, sobrinos y parejas trans. (GONZÁLEZ GIL, 2017)

Leoni (2017) analisa precisamente a produção deste não-local trans na intersecção de gênero e sexualidade não normativas. O autor enuncia enquanto homem trans ou pessoa trans masculina e denuncia as interpretações normativas sobre sua identidade. Cabe ressaltar que através da sua descrição, podemos observar as incoerências das próprias leituras hegemônicas sobre o corpo trans e sua sexualidade - o leem como um homem, por vezes gay, que "deveria" ser uma "super caminhoneira". Tais leituras hegemônicas impedem com que as vivências das pessoas trans façam sentido, tenham uma coerência "lógica". A sexualidade das pessoas trans, sob este viés normativo, é usada como forma de deslegitimar as suas próprias identidades de gênero.

A sexualidade para a pessoa trans é muito difícil porque não importa o que você seja, sempre vão encontrar uma forma de te desqualificar. Se você é trans e gay, você é só uma menina confusa. Se você é trans e hétero, você está tentando fugir da lesbofobia. Se você é trans e bi, então porque você não continua mulher? Nunca tem uma aceitação da sexualidade. As pessoas acham que trans é uma sexualidade por si só, que é uma super caminhoneira ou um super viado. Eu, sendo como eu sou e me comportando como eu me comporto, todo mundo me cobra masculinidade e me cobra heterossexualidade, algo muito distante da minha vivência. Em todos os lugares que eu já frequentei, eu não me lembro quando as pessoas acharam que eu era hétero. Mesmo quando eu sou lido como homem, eu sou lido como gay. Para as pessoas eu sou uma super lésbica, só que não faz sentido porque eu também fico com homens. Então as pessoas me veem e soltam a famosa máxima: "Então por que não continua menina?" Qual é lógica de achar que eu estou "virando menino" para ficar com mulheres? Lésbicas não existem? É um apagamento só, e as pessoas 
presumem o que você é. Estruturalmente as pessoas não estão treinadas para ver o gênero distinguido da orientação sexual. Para eles o homem é homem porque pega mulher, a mulher é mulher porque pega homem, como se fosse uma relação mútua. Eles enxergam como se um completasse o outro e isso impede a compreensão do trans. Nessa lógica o que é o trans? O que ele completa? Trans só vai ficar com trans para completar o trans? Não tem lógica. (LEONI, 2017)

Se a heterossexualidade das pessoas trans e seus parceiros é questionada quanto à sua legitimidade, com a homossexualidade também não é diferente, mesmo que esta deslegitimação incida sob outros aspectos da corporeidade e objetos discursivos. O corpo

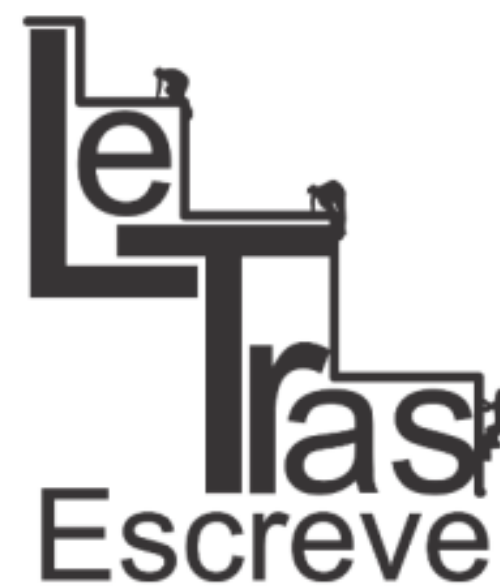

(ISSN 2238-8060) transgênero, desta forma, não é visto suficientemente inteligível para suportar nem uma verdade plena em relação à heterossexualidade nem em relação à homossexualidade.

Quanto à bissexualidade, há uma crença espontânea acerca da sexualidade dos parceiros de pessoas trans. Parceiros de pessoas trans costumam serem vistos como bissexuais pelo fato das pessoas trans serem frequentemente vistas como pessoas portadoras de atributos tanto masculinos e femininos. Tal concepção sobre bissexualidade é também potencialmente problemática, já que relega os corpos transgêneros a um lugar de excepcionalidade na forma como a sexualidade é simbolizada que beira o exotismo e cissexismo ${ }^{15}$.

Alves (2013a) afirma que mulheres trans tem muita dificuldade em se assumirem como lésbicas ou bissexuais. Isto porque, como analisa a autora, a heterossexualidade é presumida como compulsória $^{16}$ para que as identidades transgêneras sejam inteligíveis: se al-

\footnotetext{
${ }^{15}$ Designamos por cissexismo as crenças de que os gêneros, assim como as suas vivências e questões políticas, das pessoas transgêneras sejam, de alguma forma, menos verdadeiros e legítimos do que os gêneros, vivências e questões políticas das pessoas cisgêneras.

${ }^{16}$ Cabe ressaltar que, em se tratando do recorte analítico que diz respeito às identidades
} 
guém deseja pertencer a um gênero diferente daquele que foi designado ao nascer, automaticamente vincula-se a pressuposição de que esta pessoa se atraia afetivamente/sexualmente por pessoas do gênero "oposto" em relação ao gênero que ela se identifica. A autora afirma que o feminismo foi de suma importância para o seu processo de auto aceitação.

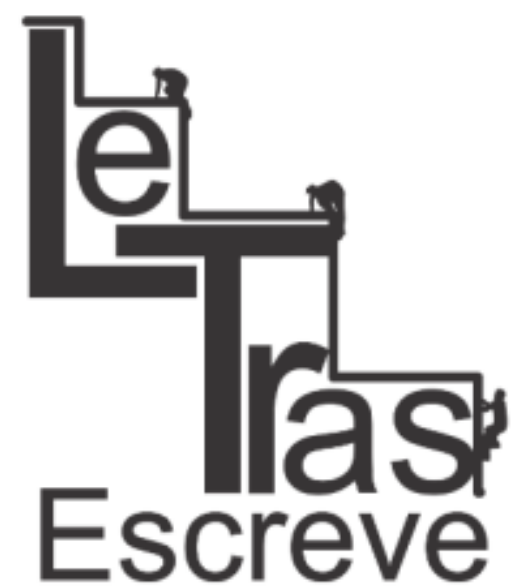

(ISSN 2238-8060)

O estigma da deslegitimação identitária (mulheres trans* não são mulheres ou são menos mulheres porque se relacionam com outras mulheres) sempre foi (e é) muito forte nos espaços médicos e nos grupos trans*. Só comecei a repensar minha sexualidade quando entrei em contato com o feminismo, alguns anos atrás - e então fui me livrando de certos preconceitos, entre eles uma espécie de "translesbofobia" que eu tinha, me impedindo de relacionar com outras mulheres. O feminismo foi essencial para essa descoberta, me permiti amar e ser amada por outras mulheres, sentir os prazeres do sexo lésbico, as maravilhas dos "ambientes femme" cheios de carinhos e afetos. (ALVES, ibid.)

Alves (2013a) designa como "genitalização" a importância usualmente atribuída aos genitais como um "elemento essencial do afeto" ou como uma "categoria fundante das relações interpessoais" e a forma como certos signos corporais se tornam "premissas para nossas relações". Questionar a centralidade do genital para a definição da sexualidade, neste sentido, é fundamental para que as pessoas trans passem a ocupar uma posição inteligível, seja na homossexualidade, heterossexualidade ou bissexualidade. Uma das premissas centrais deste questionamento é de que "homossexualidade não requer simetria genital e nem heterossexualidade requer assimetria genital" (ALVES, 2013b).

transgêneras, a heterossexualidade é não apenas presumida como compulsória para a inteligibilidade de seus gêneros, como também é desqualificada, tendo em vista que o corpo transgênero é marcado por uma falta de verdade em relação ao corpo cisgênero.

https://periodicos.unifap.br/index.php/letras

Macapá, v. 7, n. I, Io semestre, 2017. 
Alves (2013c) também nos mostra que uma das formas pelas quais a sexualidade de pessoas trans é apagada é através da noção equivocada de que as próprias identidades transgêneras seriam em si mesmas uma forma de sexualidade. Tal visão vincula-se frequentemente à noção de que a sigla LGBT refere-se a "uma coisa só", imiscuindo indiscriminadamente identidade de gênero e sexualidade. A partir da crítica a esta noção, afirma-se que não há nenhuma especificidade do campo da sexualidade que decorre exclusivamente da transexualidade (ALVES, ibid.).

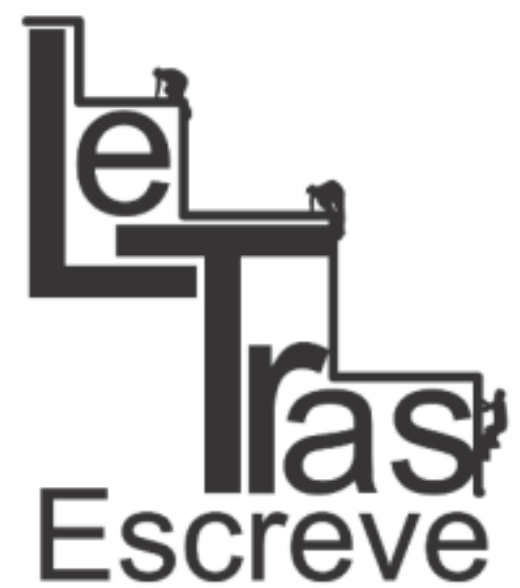

(ISSN 2238-8060)
Não faz sentido agruparmos a transexualidade com outras sexualidades. Contudo, justamente porque a transexualidade não é uma sexualidade, as pessoas trans* podem se identificar como trans* e como de uma sexualidade (ou não-sexualidade). Explico: Alguém pode ser trans* $E$ heterossexual; trans* E gay; trans* $\mathrm{E}$ lésbica; trans* $\mathrm{E}$ bissexual; trans* $\mathrm{E}$ pansexual; trans* $E$ assexual etc. $O$ fato de uma pessoa escolher se identificar como de outro gênero, não implica que a) ela tenha uma sexualidade "natural" inscrita no corpo/identidade "original" que irá ser "transportado" com ela para a nova identidade; e b) que ela tenha que assumir "naturalmente" a heterossexualidade do gênero no qual ela identifica. (ALVES, ibid.)

Grimm (2017) define a heteronormatividade como um "conjunto de estruturas que circunscrevem os relacionamentos sexoafetivos entre homens e mulheres como única verdade e possibilidade", assim como os processos de invisibilização e subalternização dos relacionamentos homossexuais. A autora analisa a relação entre a heteronormatividade e cisnormatividade na deslegitimação da lesbiandade de mulheres trans.

A heteronormatividade presume a cisnormatividade, na sua legitimação dos relacionamentos heterossexuais. Isso é: pressupõe também a inexistência 
ou a marginalização de pessoas trans - pressupõe também a possibilidade de "curar" pessoas trans, pra que se reconheçam dentro da identidade que Ihes foi assignada pelo estado [...] E se trata, também, de heteronormatividade quando mulheres trans lésbicas são lidas enquanto "homens heterossexuais que se vestem de mulher". Quando se nega às mulheres que amam e se relacionam com mulheres trans o reconhecimento de que estão se relacionando com uma mulher - negando que se trata de um relacionamento entre mulheres - pressupõese a heterossexualidade como um destino determinado pelos corpos ali envolvidos. A heteronormatividade se amarra, aqui, com o cissexismo - pelo pressuposto de que nossas genitálias ocupam um caráter central na definição de quem somos - de modo a pressupor que nossas orientações afetivas se definem pela genitália. (GRIMM, ibid.)

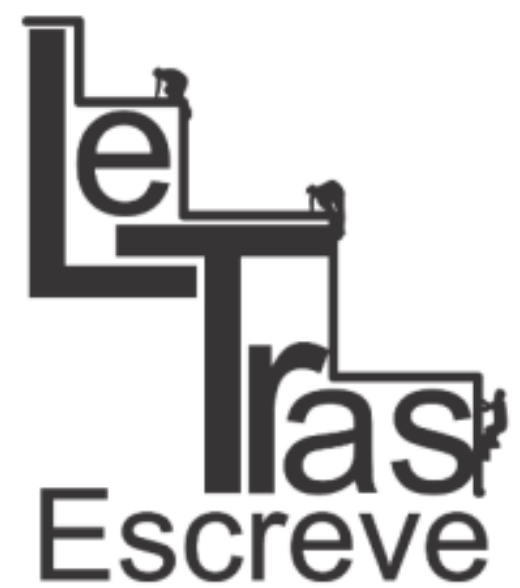

(ISSN 2238-8060)

\section{Considerações Finais}

Podemos concluir que nem todas as heterossexualidades e homossexualidades são as mesmas, o que implica dizer, frente aos relatos que analisamos neste artigo, que nem toda sexualidade é cisgênera, ou seja, nem toda sexualidade centra-se em parceiros e cônjuges cisgêneros e suas respectivas corporeidades para "fazer sentido" ou simplesmente para existir. Diante os relatos de pessoas trans, que possuem tanto um teor descritivo de suas vivências quanto crítico e analítico das normas sociais, podemos compreender que não apenas a heterossexualidade é compulsória, mas também é a cisgeneridade, assim como a norma não ser apenas heterossexual, ela também é cisgênera.

Neste processo, podemos observar como o imbricamento de questões de gênero e sexualidade - no que diz respeito à analítica das normas heterossexuais e cisgêneras - não é óbvio quando tratamos de vivências transgêneras, tendo em vista que os estudos femi- 
nistas e de gênero ainda parecem tratar estas duas questões de maneira ainda estanque - ora desconsiderando as nãoheterossexualidades a partir de corporeidades trans, ora presumindo as não-cisgeneridades a partir de vieses cissexistas (que conjugam tanto a compulsoriedade como a deslegitimação da heterossexualidade).

\section{Referências}

ALVES, Hailey Kaas. 2013a. Sobre ser mulher trans* e bissexual: uma experiência pessoal. Disponível em: http://transfeminismo.com/so bre-ser-mulher-trans-e-bissexual-uma-experiencia-pessoal/ Visualizado em 05/01/2017.

- A genitalização das pessoas e dos relacionamentos. 2013b.

Disponível em: https://generoaderiva.wordpress.com/2013/05/05/agenitalizacao-das-pessoas-e-dos-relacionamentos/ Visualizado em 05/01/2017.

. Algumas considerações sobre a questão das mulheres trans* lésbicas, bissexuais e pansexuais. 2013c. Disponível em: https://generoaderiva.wordpress.com/2013/08/02/algumas-consi deracoes-sobre-a-questao-das-mulheres-trans-lesbicas-bissexuais-epansexuais/ Visualizado em 05/01/2017.

ARAÚJO, Maria Clara. A solidão da mulher trans negra. 2015a. Disponível em: http://blogueirasnegras.org/2015/07/16/solidao-damulher-trans-negra/ Visualizado em 05/01/2017.

. Por que os homens não estão amando as mulheres trans? 2015b. Disponível em: http://transfeminismo.com/por-que-oshomens-nao-estao-amando-as-mulheres-trans/ Visualizado em 05/01/2017. 


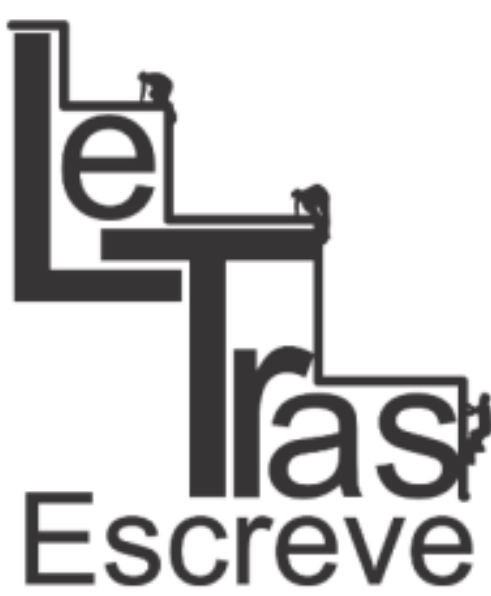

(ISSN 2238-8060)
BERLANT, Lauren; WARNER, Michael. Sex in public. Critical Inquiry, v. 24, n. 2, p. 547-566, 1998.

BUTLER, Judith. Problemas de Gênero: feminismo e subversão da identidade. Rio de Janeiro: Civilização Brasileira. Tradução de Renato Aguiar. 2003.

GONZÁLEZ GIL, Mati. ¿Qué es el amor para las personas trans? 2017. Disponível em: https://www.vice.com/es_co/article/que-es-el-amorpara-las-personas-trans Visualizado em 12/01/2017.

GRIMM. Raíssa Éris. Heteronormatividade e transfobia - sobre a invisibilidade trans lésbica. 2017. Disponível em: https://sapaprofana wordpress.com/2017/02/01/heteronormatividade-e-transfobiasobre-a-invisibilidade-trans-lesbica/ Visualizado em 10/02/2017. HOCQUENGHEM, Guy. El deseo homosexual. In: El deseo homosexual. Terror anal. HOCQUENGHEM, G.; PRECIADO, P.B. España: Melusina, pp. 21-131. Editorial Melusina, 2009.

INTERNATIONAL COMMISSION OF JURISTS (ICJ). Yogyakarta Principles - Principles on the apllication of international human rights law in relation to sexual orientation and gender identity. 2007.

JACKSON, Stevi. Interchanges: Gender, sexuality and heterosexuality: The complexity (and limits) of heteronormativity. Feminist theory, v. 7, n. 1, p. 105-121, 2006.

LEONI, Guilherme de Paula. 2017. Publicação pública no Facebook da página Adur-RJ SSind. Disponível em: https://www.facebook.com/ Adurrjssind/photos/a.1250036818413463.1073741857.556934177 723734/1266200693463742/?type=3\&theater Visualizado em 06/02/2017.

LOMANDO, Eduardo Marodin. Processos, desafios, tensões, e criatividade nas conjugalidades de homens e mulheres transexuais. Tese de doutorado, Universidade Federal do Rio Grande do Sul. Porto Alegre.

https://periodicos.unifap.br/index.php/letras Macapá, v. 7, n. I, Io semestre, 2017.

162 
2014.

LOURO, Guacira Lopes. Pedagogias da sexualidade. In: LOURO, G. O corpo educado. Pedagogias da sexualidade. Belo Horizonte: Autêntica, 2000.

PELÚCIO, Larissa. Três casamentos e algumas reflexões: notas sobre conjugalidade envolvendo travestis que se prostituem. Estudos Feministas, v. 14, n. 2, 2006.

RICH, Adrienne. Heterossexualidade compulsória e existência lésbica. Bagoas - Estudos gays: gêneros e sexualidades, v. 4, n. 05, 2010.

ROXY, Natasha. Por que os homens não amam as travestis? 2017. Disponível em: http://www.revistaforum.com.br/osentendidos/ 2017/01/14/por-que-os-homens-nao-amam-travestis/ Visualizado

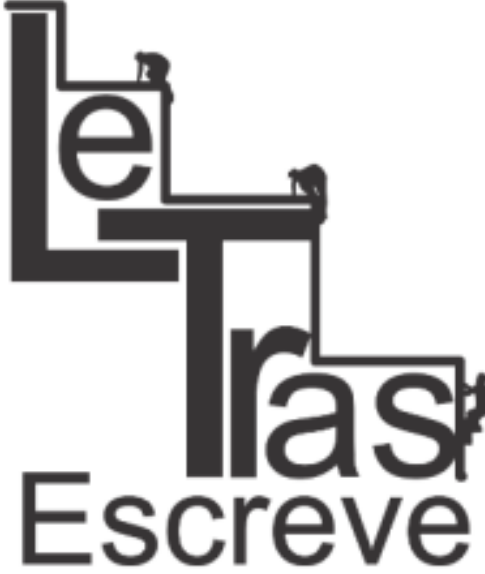

(ISSN 2238-8060) em 10/02/2017.

SANTOS, Mario Henrique Alves de. Quando homens cis amam mulheres trans. 2017. Disponível em: http://www.revistaforum.com.br/ osentendidos/2017/01/29/quando-homens-cis-amam-mulherestrans/ Visualizado em 10/02/2017.

SEDGWICK, Eve Kosofsky. A epistemologia do armário. Cadernos Pagu, v. 28, n. 1, p. 19-54, 2007.

SOARES, Milene. Homens parceiros de transexuais: diálogo fenomenológico de vivências afetivo-sexuais. Dissertação de mestrado, Universidade de São Paulo. Ribeirão Preto, 2012.

TANNEHILL, Brynn. Dois pesos e duas medidas são fatais para transgêneros. Tradução de Roberto Maxwell. 2014. Disponível em: http://blogueirasfeministas.com/2014/01/dois-pesos-e-duasmedidas-sao-fatais-para-transgeneros/_Visualizado em 10/02/2017. VERGUEIRO. Viviane. Por inflexões decoloniais de corpos e identidades de gênero inconformes: uma análise autoetnográfica da cisgeneridade como normatividade. Dissertação de Mestrado, Universidade 
Federal da Bahia, Salvador, 2016.

WARNER, Michael. Introduction: Fear of a Queer Planet. Social Text, n. 29, p. 3-17, 1991.

WEEKS. Jeffrey. O corpo e a sexualidade. In: LOURO, G. O corpo educado. Pedagogias da sexualidade. Belo Horizonte: Autêntica, 2000.

Recebido em 04/03/2017

Aceito em 10/04/2017

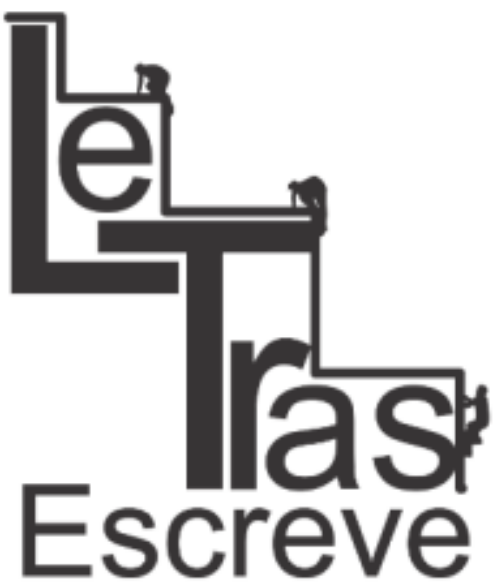

(ISSN 2238-8060) 